ISSN 1112-9867

http://www.jfas.info

\title{
THE FEASIBILITY AND BENEFITS OF USING HIGH-STRENGTH CONCRETE FOR CONSTRUCTION PURPOSES IN EARTHQUAKE PRONE AREAS
}

\author{
J. Davari, M. Jazayeri Moghdas," M. Mahdavi Adeli
}

Department of Civil Engineering, Shoushtar Branch, Islamic Azad University, Shoushtar, Iran

\author{
Published 11 June 2016
}

\begin{abstract}
In recent years, concrete technology has benefited from great advances and evolutions that lead to emergence of new concrete with different properties. One of the most important of these concretes is high strength concrete (HSC). The emergence of HSC has made possible to high-rise buildings and towers with architectural art and delicacy and it is expected that in the next few years, there is the possibility of using HSC in wider areas. Examining the studies on this type of concrete, this paper has deal with the feasibility and benefits of using HSC for construction purposes in earthquake prone areas. The results of this study show that in case of respecting the bylaw constrains and conformity of new bylaws with this type of concrete, it is hoped to use it as a reliable option for safe construction in seismic areas.
\end{abstract}

Keywords: Concrete, High-Strength, Construction, Seismic Area, Feasiblity

Author Correspondence, e-mail: mehmahad@yahoo.com

doi: http://dx.doi.org/10.4314/jfas.v8i2s.35

\section{INTRODUCTION}

Concrete is a compound material composed from various components of grain, cement and water. There are a few construction materials with this diversity, since it is possible to produce concrete with appropriate different properties according to needs not only by changing the 
amount of cement, water and grains but also with consumption of various cements and rock materials [1]. Nowadays, concrete as a main construction material is used in construction of different structures such as buildings, bridges, tunnels, dams, waterfronts, roads and other special structures. In construction of ordinary structures, the only criterion for acceptance of concrete is often its compressive strength. This might be due to the fact that concrete with satisfactory compressive strength will often have other properties at average level. In recent years, by studying the concrete structures especially in rigid and corrosive environments, the experts realized that the compressive strength of concrete cannot satisfy the whole expectations of concrete and it is required to pay enough attention to other properties of concrete especially its reliability and durability in addition to strength and load tolerance. Nowadays, in advanced industrial countries, some instructions and standards have been prepared for designing of concretes with high performance and the designers and actors are obliged to respect these instructions [2-4].

In a few recent decades, the achievement of high compressive strength in concrete has been one of the main objectives of the authorities of concrete works. According to American Concrete Institute, HSC is a concrete with compressive strength higher than $42 \mathrm{MPa}$ for concrete constructed from light weight grains. It worth noting that most concrete bylaws constrain the compressive strength of the concrete used in structures to $60 \mathrm{MPa}$; however, recently some concrete bylaws, consider the condition up to $105 \mathrm{MPa}$ as desirable [5].

It is often possible to construct concrete with compressive strength about $50 \mathrm{MPa}$ by reducing water to cement ratio up to 0.3 . The construction of concrete with high strength about 120 MPA and its use in construction of various structures especially high- rise buildings is very common in advanced countries of the world. The benefits of these concretes include high compressive and tensile strength, higher elasticity module and lower penetrability. The effective factors in achieving such high strengths in concrete is the use of resistant sand with appropriate form, increased consumed cement, constraining the size of biggest grain, the use of sand with appropriate softness module and appropriate sand to cement ratio for higher homogeneity. Moreover, it is possible to prepare more compact with less porosity complex using fine-grained material with size of less than $10 \mu$ such as silica grim [6,7]. 
In high strength concretes, one should reduce water to cement ratio to the most possible extent $(\mathrm{W} / \mathrm{C}=0.18 \sim 0.35)$, in this condition, some anhydrate cement grains that are in form of filling fine-grain materials increase density and consequently increased strength. To provide sufficient efficiency and workability in such mixtures prepared by low water, it is required to use super lubricants. Concerning the softness of HSC, it should be noted that mostly increased strength leads to increased brittleness and fragility. To increase softness of these concretes, it is possible to add short fibers to them. One of the most important points concerning the application of HSC in structures is precise attention to mixture plan, implementation method and processing. Concerning mixture plan, one should note that due to multiplicity of effective factors in HSC properties, no special mixture plan has been proposed in valid bylaws for this kind of concrete. Thus, it is required to determine mixture plan proportionate to laboratory studies and test and trial on any other valid method in practical applications of HSC. Concerning implementation, precise supervision on concrete implementation should be done using skillful workforces and proper equipment. Concrete processing should be done continuously by supplying sufficient moisture and in 20 to $25^{\circ} \mathrm{C}$ [8].

The other issue concerning HSC is that in some cases, cement consumption has increases and it might even reaches above $500 \mathrm{~kg} / \mathrm{m}^{3}$. In addition to increase in final price, this leads to some cracks due to overheat and concrete shrinkage. Due to high cracks, this concrete cannot have acceptable durability in rigid and corrosive environmental condition. Due to increased durability of these concretes, in addition to decreased consuming water and use of super lubricant, the amount of consumed cement should be reduced; instead, Pozzolanic materials such as silica fume, fly ash and Pozzolanic materials such as silica fume, fly ash and ground blast furnace slag are replaced in form of fine-grained materials.

In the present study, after precise introduction of HSC and considering its properties emphasizing on its function in seismic areas and evaluation of the tests on this kind of concrete, the economic analysis of its application in concrete buildings in seismic areas has been done and at the end, the feasibility study and the benefits of using HSC for construction of buildings in seismic areas have been studied [9]. 


\section{HSC PROPERTIES AND ITS APPLICATION}

The compressive strength of concrete is the most important quality criterion. Some factors such as specification of grains in terms of shape, texture, maximum size, the amount of consumed cement and water to cement ratio affect the compressive strength of concrete. Mostly the increase in strength of HSC in early years is more than that of ordinary concrete; however, increase of strength over time is subject to the constitutive materials and concrete processing manner. The considerable point in HSC processing is to supply sufficient moisture and temperature so that the cement hydration would be durable over the processing period. Tensile strength of concrete is one of the other mechanical features. Usually, tensile strength of concrete is about 10-20\% of its compressive strength; thus, all effective factors on compressive strength are also effective on tensile strength and the tensile strength of HSC is much more than ordinary concrete. Since, the concrete strength depends to a great extent on its density; it is required to make the fluidity of mixture to the extent that it provides the possibility of achieving an appropriate density. By adding appropriate amount of super lubricant of micro silica and similar materials in in concrete mixture, it is possible to supply the intended efficiency. Strain-stress curve and elasticity module of concrete are the other mechanical features of concrete. The shape of strain-stress curve of HSC compared to ordinary concrete is more linear of lower slope. In recent years, the application of HSC has become common in bridges, buildings and some marine structures which is due to its benefits in increase of strength, stability, rigidity and also bigger bays and lower weight. Concerning buildings, in elements under pressure such as columns, the application of HSC is determining since concrete strength plays significant role in capacity and plasticity of elements [10].

The first application of HSC in buildings' column dates back to late 60s in Chicago (United States) which was used for weight decrease to minimize the load transmitted to foundation in sites with undesired soil specification. Nowadays, its use becomes pervasive such that in high-rise structures, the concrete with strength more than $100 \mathrm{MPa}$ is used. In late $80 \mathrm{~s}$ and early 90s, several main HSC structures were built: in Seattle a 220-m building has been built sing $115 \mathrm{MPa}$ concrete, in Norway and Britain, HSC was widely used in construction of big coastal structures. In Spain, the first use of HSC was for two narrow pedestrian bridges with 
$80 \mathrm{MPa}$ concrete in Montjuic that was built for Olympic 1992 [11,12].

Regardless of its main benefits, we know that HSC has higher fragility compared to ordinary concrete; thus, its application has not been much in seismic areas. Due to fragility of this kind of concrete, some bylaws has prevented the use of HSC in areas with high seismicity such as Algeria bylaw [1] that has declared concrete strength limited to $45 \mathrm{MPa}$ in seismic areas.

\section{APPLICATIONS OF HSC IN SEISMIC AREAS}

In most common structures and other structures that are recently designed, HSC (f_c $\left.c^{\wedge}>50 \mathrm{MPa}\right)$ has wide applications. Economic efficiency, strength, rigidity and high durability are the main reasons for frequent applications of this kind of concrete [13]. Currently, structure engineers are studying the benefits of using this material in various applications. The main objectives of this paper are the study of the application of HSC in seismic resistant frames and the study of the behavior of main elements constructed with HSC in these structures. The present study done by Mendis and Panagopolos performs the comparison between seismic performances of a construction frame when HSC has been used instead of concrete with ordinary strength $[14,15]$.

\subsection{Case Study}

In this study, a 6-storey building shown in figure 1 has been selected and designed for two different plasticity levels according to Australia concrete bylaw called 3600 and earthquake bylaw called 1170.4. The response revision coefficients $(\mathrm{R})$ for ordinary and average moment resisting frames have been respectively considered 4 and 6 . The specification of frame and dimensions of sections has been shown in table 1. To compare the structure responses, columns have been designed by concretes of 50 and $100 \mathrm{MPa}$ strength. The arrangement of sections has been shown in table 2. For designing purpose, nominal strength of bars was used. Moreover, analysis was done by arrangement of bars; however, strength of 650 MPA was considered as yield upper limit [16,17].

For a realist estimation of frames, the rigidity value of members should be close to yield value so that the joints' formation has the possibility of conformity with assumed distribution. The effective secondary anchor for beams is $I_{e f f}=0.4 I_{g}$ and for columns $I_{e f f}=0.6 I_{g}$ [Paulay 
and Priestley, 1992] (The moment of inertia for beams and columns were modified as above). In this study, the seismicity intensity has been considered in low to average seismicity range so that maximum ground acceleration (with return period of 500 years) is $a=0.11 \mathrm{~g}$. The earthquake resulting force in the balance of each story was obtained using the reverse triangular load pattern that is the basis of static analysis corresponding to bylaw (AS 1170.4). The distribution of lateral forces proportionate with gravity load of structure (dead load $+40 \%$ live load). The gravity loads governs the designing of structure so that the size of beams doesn't change. Decrease in dimensions of columns that was due to using HSC doesn't lead to significant reduction in earthquake load (decrease of gravity loads for OMRF and IMRF frames is $1.8 \%$ and $0.8 \%$, respectively).
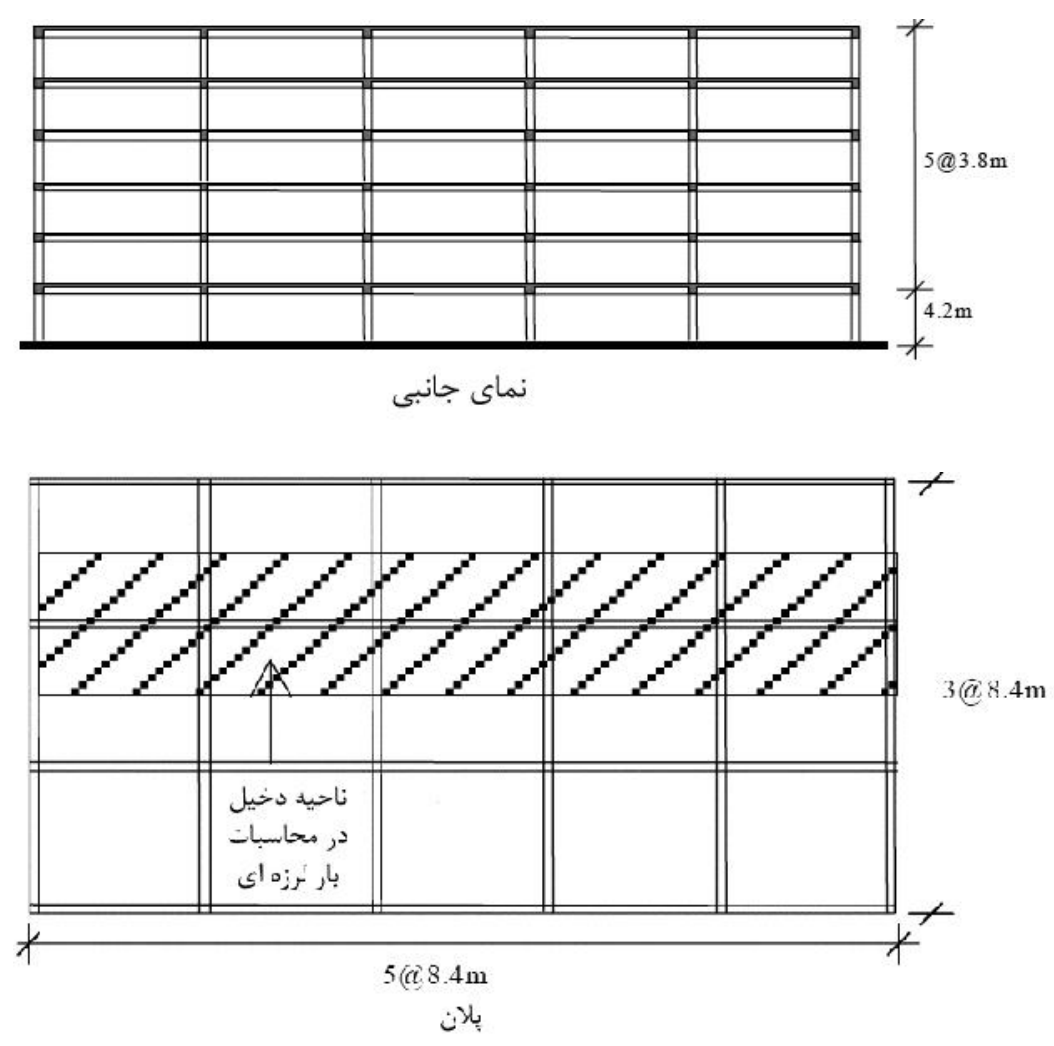

Fig.1. Configuration of structure 
Table 1. Types of frame and size of sections

\begin{tabular}{|c|c|c|c|c|c|c|c|}
\hline Frame & $\begin{array}{c}\text { Structural } \\
\text { type }\end{array}$ & Beam size & $\begin{array}{c}\boldsymbol{f}_{c}^{\prime} \text { beam } \\
(\mathbf{M P a})\end{array}$ & $\begin{array}{c}\text { Column } \\
\text { size }\end{array}$ & $\begin{array}{c}\boldsymbol{f}_{\boldsymbol{c}}^{\prime} \text { column } \\
(\mathbf{M P a})\end{array}$ & $\boldsymbol{f}_{\boldsymbol{s y}}$ plan & Analyzed $\boldsymbol{f}_{\boldsymbol{s y}}$ \\
& & & & & \\
$(\mathbf{M P a})$ & $(\mathbf{M P a})$ \\
\hline 1 & OMRF & $400 \times 700$ & 32 & $500 \times 500$ & 50 & 500 & $500 \& 650$ \\
\hline 2 & OMRF & $400 \times 700$ & 32 & $400 \times 400$ & 100 & 500 & $500 \& 650$ \\
\hline 3 & IMRF & $400 \times 700$ & 32 & $450 \times 450$ & 50 & 500 & $500 \& 650$ \\
\hline 4 & IMRF & $400 \times 700$ & 32 & $400 \times 400$ & 100 & 500 & $500 \& 650$ \\
\hline
\end{tabular}

Table 2. Details of the columns of ground floor and bars of first floor

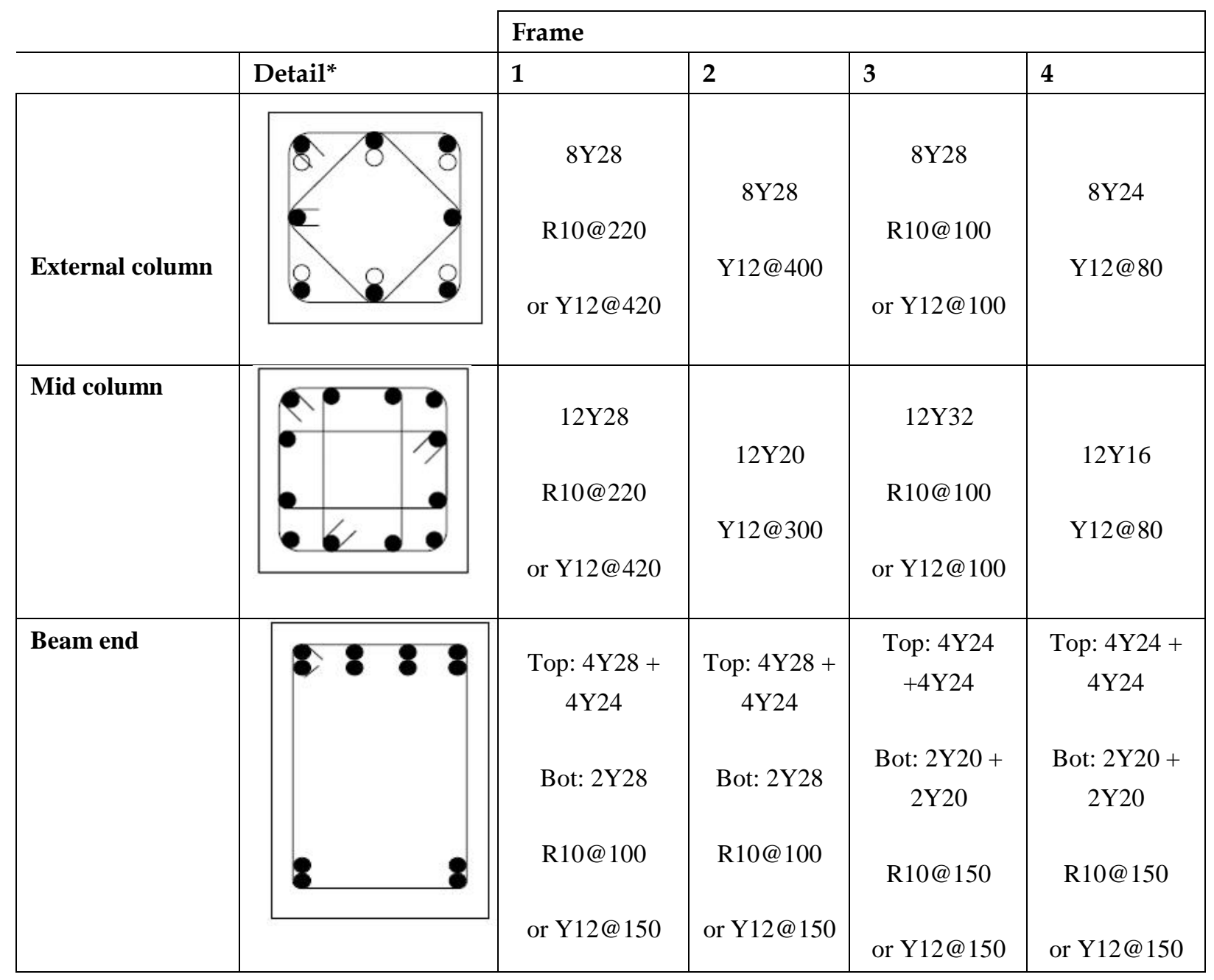

\subsection{Results of Dynamic Analysis}

El Centro (PGA=0.33 g) was selected as a powerful earthquake. Time series analysis was performed using RUAMOKO nonlinear software [15]. Members were modeled using 
standard elements in the program for beam and column [17,18].

To show the behavioral nature of structures designed for various plasticity levels, some response parameters will be presented follow. Roof displacements were not much different for structures and for every four studied structures they are less than $0.85 \%$ of the height of structure (0.0085h). De Stefano et al [16] proposed that maximum structural damage happen when the roof level experiences approximate displacement of $0.01 \mathrm{~h}$. Thus, it is recommended that in the studied frames, the damage is balanced. The analyzed frames with effective rigidity showed more changes in displacement (with magnitude of 1.38\%) that means higher damage levels $[19,20]$.

The above study shows that increase in compressive strength of concrete, dimensions of sections and the ratio of reinforce in columns could be considerably decreased. Yet, in this study, the frames constructed from HSC column proportionately satisfy the demand plasticity. In spite of decrease in the dimensions of columns, maximum displacement decreased due to high elasticity module of members constructed from HSC and earthquake forces. The use of HSC has other benefits such as improvement of the shear capacity of columns, enhancement of the connections between beams and columns and the possibility of using reinforcements with bigger diameter for transfer of rotational plasticity in flexural members [21].

\section{THE ECONOMIC STUDY OF HSC}

Mohammad Sheikh [22] has tested HSC with different mixtures in 2008 with the aim of investigating the effect of various parameters in costs of concrete.

This study is of a research group about real modeling of HSC cost in several stories buildings (12 stories) especially in columns' members (corner, side and inside columns). To achieve this objective, 5 classifications of HSC have been presented as follow:

Normal strength concrete, 35 MPA, NSC

Medium strength concrete, MSC, $56 \mathrm{MPa}$

High strength Concrete, HSC, 62MPa

Very High strength Concrete, VHSC, 98MPa

Ultra high strength concrete, UHSC, $120 \mathrm{MPa}$ 
The slump of these concrete samples is in range of 100 to $120 \mathrm{~mm}$. Put reincefores in form of minimum reinforcement ratio and maximum reinforcement ratio was considered as two designing criteria. In addition, the evaluation of economically of HPC was done by consideration of instructions that perform the early evaluation of total construction cost.

The results showed that designing with maximum reinforcement decreases total cost of columns up to $17 \%, 23 \%, 39 \%$ and $49 \%$ in respect to columns constructed from NSC concrete. In other words, designing with minimum reinforcement decreased total cost up to $34 \%, 39 \%, 49 \%$ and $52 \%$ compared to NSC concrete. Finally, the designing of HPC columns with minimum reinforcement value lead to more economic design compared to the condition of maximum reinforcement value [23].

Various compositions of HPC were tested for studying the effect of various parameters on their costs and total cost. According to experimental results, the analytic evidences and the relative comparisons, the following results were obtained.

- The use of minimum reinforcement values made considerable $50 \%$ reduction in total costs.

- The increase of the strength of columns constructed from HPC lead to reduction of total cost of columns.

- Considerable reduction was achieved in total cost of columns due to the use of HPC especially when minimum reinforcement values were used; yet, total cost reduction of all columns (corner, side and inside columns) varied in $32 \%$ to $57 \%$ area concerning the strength of used concretes (56 to $100 \mathrm{MPA}$ ) compared to strength of NSC concrete which was $35 \mathrm{MPa}$.

- Optimum and economic design of corner columns was achieved when using UHSC with minimum reinforcement ratio.

- The application of VHSC with minimum reinforcement ratio lead to economic and optimum design for side and inside columns.

- At the end, the application of high quality materials doesn't increase the costs of building; instead, the use of high quality materials leads to cost reduction that creates a durable and low cost structure concerning increased time. 
- The results of this investigation show that the use of HSC leads to percentage reduction of reinforcement used in all tested samples about $50 \%$.

Nageh and Bashandy [48] studied the possibility of forming HSC with economic materials in 2013. The main aim of this study is investigation and evaluation of Ultra high strength concrete using economic materials. Reactive powder concrete (RPC_ was used as one type of UHSC. The mechanical properties of this kind of concrete was evaluated and the effect of using various cement, micro-silica and the ratio of dimensions of new steel fibers as reinforcement was studied for this type of concrete. The compressive strength of $154 \mathrm{MPa}$, indirect tensile strength of $12 \mathrm{MPa}$, elasticity module of $45 \mathrm{GPa}$, shear strength of $30 \mathrm{MPa}$ were obtained for PRC that include $800 \mathrm{~kg} / \mathrm{m} 3$ cement and $30 \%$ cement weight of micro-silica. The results showed that increased cement and micro-silica and also increase of steel fibers on compressive strength, elasticity module and indirect tensile strength makes improvement. Moreover, big positive effect on shear strength was also shown.

According to the results of this study, the following main results were obtained:

1. Ultra-high strength concrete could be produced using cheap and accessible materials in North Sinai (Egypt).

2. Compressive strength of $154.5 \mathrm{MPa}$, indirect tensile strength of $11.98 \mathrm{MPa}$, elasticity module of $45.1 \mathrm{GPa}$ and bending strength of 30.26MPA were achieved for reactive concrete samples including RPC with $800 \mathrm{Kg} / \mathrm{m} 3$ cement and $30 \%$ cement weight micro-silica.

3. Increased micro-silica improved compressive strength, elasticity module, tensile and bending strength of RPC concrete in various ages.

4. It is recommended to use micro-silica up to $30 \%$ cement weight.

5. It is recommended to increase the cement amount, compressive strength, and elasticity module, tensile and bending strengths of PRC in various ages.

6. By adding metal fibers up to $40 \mathrm{Kg} / \mathrm{m} 3$, compressive strength of 7 and 28 -day concretes improved 7\% compared to RPC. Moreover, elasticity module of 7 and 28 days concrete improved up to $18 \%$ compared to ordinary RPC concrete and the 
tensile strength of 28-day concrete improved about $30 \%$ and the bending strength for 7 and 28 days concretes improved about $190 \%$.

7. It is recommended to use mental fiber as a promoting material in RPC.

8. Finally, it is possible to produce economic RPC using the materials in North Sinai, moreover, it is possible to construct prefabricated ultra-high strength with extraordinary mechanical properties.

\section{DISCUSSION AND CONCLUSION}

In recent years, great advances and evolutions has occurred in concrete technology use result is the emergence of new concretes with different properties. One of the most important of these concretes is HSC. The emergence of HSC has provided the possibility of constructing high-rise concrete buildings and towers with architectural art and delicacy. Although, nowadays application of HSC is not wide and intertwined with construction of high-rise structures and concrete bridges and some special structures; it is expected to see the application of HSC in wider areas. To achieve this objective, it seems necessary to include constrains in using HSC clearly in concrete bylaws by reconsideration of designing regulations.

In following, some of the main results of this study are presented:

Increase in compressive strength of concrete could lead to considerable reduction of the dimensions of sections and the ratio of reinforcements in columns. This problem changes the equilibrium in bending capacity of beam and column that could in itself change the response from wide beam joint to wide column joint. Yet, in this study, the frames constructed from HSC column appropriately satisfy the demand plasticity. The effects of using concrete with different grades in seismic behavior of double structural systems (wall-frame) have been investigated. To this end, a 10-storey building with concrete of grades $30 \mathrm{MPa}, 60 \mathrm{MPa}$ and 90 MPa was designed as representative of concretes with normal, average and high strengths. In addition, the seismic performance of buildings has been evaluated using push-over analysis and the values of control point was obtained using Euro code 8 bylaw.

The displacement based method was considered better method since it is able to determine the 
required plasticity in $\mathrm{HSC}$ to be used in designing. In this case, relative drift, total displacement and demand strength were strictly achieved that indicate proportionality of method.

The results of analyses for various states showed that the use of longitudinal reinforcement leads to improvement of concrete column function against lateral load, increases energy index that are all effective in plasticity and column capacity. Concerning the studies, the percentage of longitudinal reinforcement 3.6 is proper for UHSC columns. The comparison of compressive strength and other cases explained in the paper leads to improved performance of concrete column against lateral loads that are all effective in plasticity and column capacity to some extent.

The crushing of cover of concrete sections made considerable reduction in strength of members. It is observed that damage in columns with big and average section was more severe compared to columns with small section. The results of testing HSC columns with spiral armature show that the capacity of relative lateral displacement of these columns increases in respect to reduction of compressive force from $0.43 \mathrm{P} 0$ to $0.22 \mathrm{P} 0$ to $5 \%$ to $8 \%$.

P- anchor applied on moment resisting frames could achieve critical level. The secondary anchors due to effects of P- were reported in the studied columns in 1/3 values of applied anchors in condition when lateral drift was $2 \%$. Moreover, at this time, the columns were under axial compressive load of $0.43 \mathrm{P} 0$. Single circular armatures are effective the same as spiral armatures in constraining HSC columns on the condition that the end of armature is bent and controlled in concrete core; although, spiral armatures are more effective in stability of longitudinal reinforcements in stages later than non-elastic deformations.

Cylindrical columns with HSC equipped with FRP show more plastic behavior against lateral loads of earthquake such that in this study, the columns showed strength up to $12 \%$ lateral load drifts. The strains obtained from the results of test in this paper showed that the strain in samples is constrained up to $4 \%$. In some samples, in rupture state, rupture strain is observed up to $1.5 \%$. The plasticity of columns decreases by increase of axial load to axial column capacity ratio P/P0 and compressive strength of concrete (f_c). During the tests, in completely similar condition, it was observed that HSC columns show more lateral drift 
capacity than NSC columns.

Transverse tensile strength in FRP is created due to combination of bending and shearing. The use of these materials in columns leads to increased strength and tensile capacity of concrete and increases shear strength of concrete.

\section{REFERENCES}

[1] Priestley M. J. N., Calvi G. M., and Kowalsky M. J., Displacement Based Seismic Design of Structures, IUSSPRESS, Pavia, Italy, 2007.

[2] ACI 341.3R-07, "Seismic evaluation and retrofit techniques for concrete bridges", American Concrete Institutive, USA, 2007.

[3] ACI itg34R-07, "Report on Structural Design and Detailing for High-Strength Concrete in Moderate to High Seismic Applica- tions", American Concrete Institute, USA, 2007.

[4] EN-1992, "Eurocode 2: Design of concrete structures", Comité Europeen de Normalisation, Brussels, 2004.

[5] ACI 318M (1995): Building Code Requirements for Reinforced Concrete, American Concrete Institute, USA. ACI-ASCE Committee 352 (1996), Draft, Recommendations for design of beam-column-slab connections in monolithic reinforced concrete structures, Detroit, USA

[6] Paulay, T. and Priestley, M. (1992), Seismic design of reinforced concrete and masonry buildings, John Wiley \& Sons, New York.

[7] Carr, A.J. (1999), "RUAUMOKO”, Computer Program Library, University of Canterbury.

[8] Allena S, Newtson M, Ultra-high strength concrete mixtures using local materials. In: Concrete sustain conference; 2010.

[9] Kwan A., Lam J., Effectiveness of adding confinement forductility improvement of high-strength concrete columns, J EngStruct 32 (2010) 714-725.

[10] Kang S., Lee Y., Park Y., J. Kim, Tensile fracture properties ofan ultra high performance fiber reinforced concrete with steelfiber, J Compos Struct (2009). 
[11] Belal A., El-Karmoty Z., Abdelrahman A., El-Dieb A., Bahnasawy H., Okba S. The behavior of high strength reinforced concrete columns under axial and cyclic lateral loads, J HBRC 6 (2010) 71-79.

[12] Khattab E. Production of ultra high strength concrete using local materials and its application in axially loaded columns. Ph.D thesis. Ain Shams University; 2010.

[13] Elrakib T. Behavior of concrete columns retrofitted by fiber reinforced polymers under axial and cyclic loads. Ph.D thesis. Benha University; 2005.

[14] Paultre P., Legeron F., Behavior of high-strength concretecolumns under cyclic flexure and constant axial load, ACI Struct 97 (2000) 591-601.

[15] Calabrese A (2008) Numerical issues in distributed inelasticity modelling of RC frame elements for seismic analysis. MsC, Istituto Universitario di Studi Superiori di Pavia, Università degli Studi di Pavia, Pavia

[16] Alemdar BN, White DW (2005) Displacement, flexibility, and mixed beam column finite element formulations for distributed plasticity analysis. J Struct Eng 131(12):1811-1819

[17] Filippou FC, Fenves GL (2004) Methods of analysis for earthquake-resistant structures. In: Bozorgnia Y, Bertero VV (eds) Earthquake engineering: from engineering seismology to performance-based engineering. Cambridge University Press, Cambridge

[18] Mpampatsikos V (2008) A critical review of the r.c. frame existing building assessment procedure according to EUROCODE 8 and Italian Seismic Code. MSc thesis, European school for advanced studies in reduction of seismic risk, rose school, Università degli Studi di Pavia

[19] Mpampatsikos V, Nascimbene R, Petrini L (2008) A critical review of the r.c. frame existing building assess- ment procedure according to EUROCODE 8 and Italian Seismic Code. J Earthq Eng 12(S1):52-82

[20] Scott MH, Fenves GL (2006) Plastic hinge integration methods for force based beam-column elements. J Struct Eng ASCE 132(2):244-252 
[21] Xiao, Y., and Wu, H. 2003. "Compressive behavior of concrete confined by various types of FRP composites jackets." J. Reinf. Plast. Compos., 2213 , $1187-1202$.

[22] Mohamed M Yousry El Shikh. "ECONOMY OF USING HIGH PERFORMANCE CONCRETEIN COLUMNS" 25 - 27 August 2008

[23] Nageh N. Melekaa, Alaa A. Bashandya, Mohamed A. Arab; "Ultra High Strength Concrete Using Economical Materials"International Journal of Current Engineering and Technology Vol.3, No.2 (June 2013)

\section{How to cite this article:}

Davari J, Jazayeri Moghdas M, Mahdavi Adeli M.The feasibility and benefits of using high-strength concrete for construction purposes in earthquake prone areas. J. Fundam. Appl. Sci., 2016, 8(2S), 532-546. 